\title{
Ampicillin Induced Oral Candidiasis: A Case Report
}

\author{
George Mathew Panachiyil, Tirin Babu, Juny Sebastian*, Mandyam Dhati Ravi
}

Department of Pharmacy Practice, JSS College of Pharmacy, JSS Academy of Higher Education and Research, Mysuru, Karnataka, INDIA.

\begin{abstract}
A six year old boy presented to the outpatient department of the hospital with complaints of dysphagia since 2 days. He was previously treated for nephrotic syndrome with hypertension and was on tablet prednisolone (40mg, once daily). From eight days prior to hospital admission, he was on injection ampicillin (500mg, three times daily) for respiratory tract infections. He was diagnosed as having oral candidiasis induced by the use of ampicillin. The oral candidiasis was managed with topical application of clotrimazole (1\%) 3-4 times daily following the withdrawal of ampicillin. The following case presents an evidence that ampicillin in therapeutic dose can be associated with oral thrush.
\end{abstract}

Key words: Ampicillin, Aminopenicillin, Oral Candidiasis, Thrush, Case Report.

\section{INTRODUCTION}

Oral candidiasis is a fungal infection affecting the oral cavity caused by different candida species. ${ }^{1-3}$ Different candida species infects oral cavity are Candida albicans, Candida glabrata, Candida guillermondii, Candida krusei, Candida parapsilosis, Candida pseudotropicalis, Candida stellatoidea and Candida tropicalis. ${ }^{4}$ Oral candidiasis is also called as oral candidosis, oral thrush, moniliais, oral mycosis, oral yeast infection or candidial stomatitis. ${ }^{1}$ There are two types of oral candidosis, the condition confined to mouth is classified as primary candidosis and which develop secondary to thymic aplasia and candidosis endocrinopathy syndrome is classified as secondary candidosis. ${ }^{1,4}$ The risk factors for developing oral candidiasis include: local factors such as impaired salivary gland function, drugs (mainly inhaled steroids, broad spectrum antibiotics), dentures, oral cancer and systemic factors include smoking, diabetes, cushings syndrome, immunosuppressive conditions. ${ }^{2,4}$

Ampicillin (a broad spectrum aminopenicillin) induced candidiasis had been identified during clinical trials. ${ }^{5}$ There is a case report of ampicillin induced oral candidiasis is available in the published literature. ${ }^{6}$
A systematic review and meta-analysis of randomized placebo controlled trials of another antibiotic of the aminopenicillin class, amoxicillin estimated an incidence of $4.42 \%$ for oral candidiasis. Amoxicillin has structural similarity to ampicillin: amoxicillin contains - $\mathrm{OH}$ while ampicillin bears $-\mathrm{H}$ on the side chain..$^{7-9}$ Broad spectrum antibiotics have the ability to create a comfortable environment for the candida fungus to proliferate by altering the local oral flora which will be restored after the cessation of the antibiotic., ${ }^{2,10}$ Identification of the predisposing factors for the growth of candida species in the oral cavity can be an important step in the management of oral candidiasis. ${ }^{1}$ A case of ampicillin induced oral candidiasis is reported here.

\section{CASE REPORT}

A six year old boy presented to the hospital with a history of periorbital and facial puffiness, abdominal distension, decreased urine output about two times/day and swelling of both upper and lower limb since nine days. He was also complained of dysphagia since two days and was not associated with any other symptoms. The
DOI: 10.5530/ijopp.12.1.13

Address for correspondence: Juny Sebastian, Department of Pharmacy Practice, JSS College of Pharmacy. JSSAHER, Mysuru, Karnataka, INDIA. Phone no: +91-9620976279 Email Id: junysebastian@jssuni. edu.in

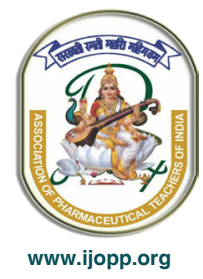


patient initially had admitted to another hospital for treatment of above symptoms, then was referred to the current hospital for further management. His past medical history revealed that he was diagnosed as having nephrotic syndrome with hypertension with respiratory tract infection eight days back and was on tablet prednisolone (40mg, once daily) and injection ampicillin (500mg, three times daily).

Vital signs on day one revealed a temperature of 37 degree Celsius, heart rate of 96 beats per minute, respiratory rate of 28 breaths per minute and blood pressure of 118/88 mmHg. On systemic examination: generalised oedema and ascites were present; respiratory examination showed dull note and decreased breath sounds present over bilateral infrascapular and infra axillary areas. On intraoral examination by dermatologist revealed whitish lesion present at left lateral aspect of tongue $(5 * 2 \mathrm{~cm})$ and small plaque $(1 * 2 \mathrm{~cm})$ present at right lateral aspect of tongue. Based on the clinical presentation and drug history, injection ampicillin induced oral candidiasis was suspected. The patient was given topical application of clotrimazole (1\%)3-4 times daily with maintenance of good oral hygiene.

His initial laboratory reports were as follows: urea $(169 \mathrm{mg} / \mathrm{dl})$, creatinine $(1 \mathrm{mg} / \mathrm{dl})$, serum albumin $2.1 \mathrm{~g} / \mathrm{dl}$, spot urea creatinine ratio $4: 1,24 \mathrm{~h}$ urine protein $93.1 \mathrm{mg} / \mathrm{m} 2 \mathrm{~h}$ and urine albumin $4+$. Anti-Hepatitis $\mathrm{C}$ virus, Hepatitis B surface antigen and rapid test for Human Immunodeficiency Virus (HIV) were negative. Upon consultation with the nephrology division, Fresh Frozen Plasma (FFP) and 20\% albumin 100ml over $5 \mathrm{~h}$ were transfused to the child. Initial treatment consisted of injection furosemide stat (20mg), injection dexamethasone (12mg, once a day), tablet lanzoprazole (30mg, once a day), Calcium Polystyrene Sulfonate (10g three time a day). Child was nebulised with salbutamol (three time a day) for difficulty in breathing. Because of persistent high BP $110 / 90$, amlodipine $(2.5 \mathrm{mg}$, once a day) was added. Diet counselling was done for nephrotic syndrome.

On fourth day at hospital, whitish lesions and burning sensation on tongue were reduced. The child responded well to the treatment with oral mouth paint within 4 days. A change to tablet prednisolone was made in the treatment.

On sixth day at hospital, oral cavity was completely cleared off the white plaques.

\section{DISCUSSION}

On analyzing the case, injection ampicillin was the most likely cause of oral candidosis. First, the time temporal relationship and clinical presentation of oral thrush. Second, to rule out any underlying systemic cause for oral candidiasis rapid test for HIV was done which revealed all values within normal range and nonreactive status for HIV. Third, steroids are known to cause oral candidiasis, but in our case, patient recovered from oral candidiasis after discontinuation of ampicillin along with symptomatic management though the steroid therapy was continuing. So the oral candidiasis can be attributed to injection ampicillin alone.

In clinically normal persons, Candidial species are relatively common inhabitant of oral cavity, gastrointestinal tract and vagina. ${ }^{1}$ The reason for around $50 \%$ of the oral candidiasis cases are due to Candida albicans. The mere presence of the fungus is not sufficient to produce the disease. $^{3}$

The penetration of the tissues by candidial species occurs only under certain circumstances which often relates a weakened immune system. Predisposing factors for candidiasis can change the harmless existence of candida species to a pathogenic state and which alters the environment in the oral cavity to an environment favourable for the candida fungal species growth. ${ }^{3}$

The risk factors that provoke the host to oral candidiasis are: old age, infancy and pregnancy with altered immunity, local trauma and poor denture hygiene and malnutrition, usage of broad spectrum antibiotics, corticosteroids and immunocompromised conditions like HIV. ${ }^{1}$ Broad spectrum antibiotics like ampicillin alter the local oral flora creating a suitable environment for candida to proliferate. This can lead to candidial overgrowth and further alteration of taste sensation and dysphagia, which results in malnutrition, delayed recovery and long term hospital stay. ${ }^{1,2,4}$ The management of oral thrush includes discontinuation of culprit drug followed by topical antifungal applications. ${ }^{1}$

A study conducted by Fitzpatrick et al. had shown an evidence of ampicillin induced outgrowth of Candida albicans. ${ }^{6}$ And also in a systematic review and metaanalysis of randomized trials, investigators found statistically significant results for candidiasis after amoxicillin administration. ${ }^{7}$ In this case, along with a proper history and clinical evaluation, patient was also analysed for underlying systemic cause. Appropriate treatment for oral candidiasis was also recommended 
after diagnosis of oral candidiasis.

\section{Assessment of ADR}

World Health Organization (WHO) algorithm for causality assessment and Naranjo's scale were used to assess the causal association between the drug intake and the reaction. Adverse drug reaction, oral candidiasis had a probable causal association to the intake of Ampicillin as per Naranjo's scale (score 6) and WHO Causality assessment algorithm as the temporal relationship is unlikely due to the intake of another drugs or any concurrent disease. Oral candidiasis induced by ampicillin is not a predicable reaction as the frequency of the reaction is not mentioned in the standard literatures. The reaction is not definitely preventable.

\section{CONCLUSION}

The following case signifies ampicillin in therapeutic dose can induce oral candidiasis in a patient. So the health care professionals must be aware of ampicillin induced oral thrush for better diagnosis and management of the same.

\section{ACKNOWLEDGEMENT}

The authors would like to thank the staffs and the postgraduate students of department of Paediatrics and department of Clinical Pharmacy, JSS Hospital, Mysuru for their support and encouragement.

\section{CONFLICT OF INTEREST}

The authors declare no conflict of interest.

\section{ABBREVIATIONS}

-OH: Hydroxyl group; -H: Hydrogen; HIV: Human Immunodeficiency Virus; FFP: Fresh Frozen Plasma; BP: Blood Pressure; WHO: World Health Organisation.

\section{REFERENCES}

1. Patil A, Susmitha HR, Basappa S, Mahesh MS. Drug-induced Oral Candidiasis: A Case Report. IJSS Case Reports and Reviews. 2016;2(12):1-4.

2. Akpan A. Oral candidiasis. Postgraduate Medical Journal. 2002;78(922):455-9.

3. Williams D, Lewis M. Pathogenesis and treatment of oral candidosis. Journal of Oral Microbiology. 2011;3(1):5771.

4. Agrawal A, Singh A, Verma R, Murari A. Oral candidiasis: An overview. Journal of Oral and Maxillofacial Pathology. 2014;18(4):81.

5. Lexicomp Online | Clinical Drug Information [Internet]. Wolterskluwercdi.com. 2018 [cited 1 October 2018]. Available from: http://www.wolterskluwercdi.com/ lexicomp-online/

6. Fitzpatrick J, Topley H. Ampicillin Therapy and Candida Outgrowth. The American Journal Medical Sciences. 1966;252(3):310-13.

7. Gillies M, Ranakusuma A, Hoffmann T, Thorning S, McGuire T, Glasziou P et al. Common harms from amoxicillin: a systematic review and meta-analysis of randomized placebo-controlled trials for any indication. Canadian Medical Association Journal. 2014;187(1):E21-31.

8. Kar A. Medicinal Chemistry. $4^{\text {th }}$ ed. New Delhi: New Age International (P) Ltd., Publishers. 2007.

9. Brogden R, Speight T, Avery G. Amoxycillin: A Review of its Antibacterial and Pharmacokinetic Properties and Therapeutic Use. Drugs. 1975;9(2):88-140.

10. Midtvedt T, Carlstedt-Duke B, Høverstad T, Lingaas E, Norin E, Saxerholt H, et al. Influence of peroral antibiotics upon the biotransformatory activity of the intestinal microflora in healthy subjects. European Journal of Clinical Investigation. 1986;16(1):11-7. 